\title{
Sensorimotor impairments of paretic upper limb correlates with activities of daily living in subjects with chronic stroke
}

\begin{abstract}
The main objective of this study was to investigate the correlations between sensorimotor impairments of paretic upper limb and the hand functions of activities of daily living (ADLs) scores in persons with chronic stroke.

This is a cross-sectional study with 19 chronic stroke survivors. Hand function was measured by the Jebsen-Taylor Hand Function Test (JTHFT). Impairments in upper extremity motor function were measured by upper limb items of Fugl-Meyer Assessment (FMA-UE). Forearm muscles strength, handgrip and pinch grip power were assessed using handheld dynamometers. Tactile sensation threshold was measured by monofilaments.

\author{
Shamay S.M. Ng, PhD' \\ Philip T.F. Tse, BSc ${ }^{1}$ \\ Jefferry C.H. Wong, BSc ${ }^{1}$
}

William W.N. Tsang, PhD ${ }^{1}$

Patrick W.H. Kwong, BSc ${ }^{1}$

Department of Rehabilitation Sciences, The Hong Kong Polytechnic University, Hong Kong (SAR), China

Significant differences were found between the affected and unaffected side in the total JTHFT scores, forearm muscle strength, handgrip and pinch grip ( $p \leq 0.017)$, but not the tactile sensation threshold. The total JTHFT scores were found to be correlated with total score of FMA-UE $\left(r_{s}=-0.789\right)$, handgrip power $\left(r_{s}=-0.588\right)$ and pinch grip power $\left(r_{s}=-0.657\right)$ on the affected side, but not the tactile sensation. The total JTHFT scores were correlated with FMA-UE scores, handgrip and pinch grip of the affected side. This is the first study in documenting the correlation between the sensorimotor impairments and JTHFT scores in persons with chronic stroke. Our findings highlights the importance of including upper limb and grip strength training in stroke rehabilitation program in order to improve hand functions in activities of daily living in patients with chronic stroke.
\end{abstract}

\section{KEY WORDS: STROKE, SENSORIMOTOR IMPAIRMENTS, HAND, UPPER LIMB, ACTIVITIES OF DAILY LIVING.}

\section{INTRODUCTION}

Stroke is one of the major causes of disability and handicap in adults. It is well documented that stroke induces a wide range of disabilities and functional limitations and limitations in hand function always occur among stroke survivors. Wade et al (1983) conducted a study to measure the recovery of upper limb function in a group of stroke subjects. Only 27 out of 92 subjects achieved full recovery two years post-stroke. The underlying impairments which caused hand function loss in patients with stroke included muscle weakness, poor coordination and altered motor pattern (Ng and Shepherd 2000).

In addition to motor impairments, somatosensory deficits are found to be associated with the slower recovery and poorer performance of functional mobility in patients with stroke (Connell et al. 2008). The possible explanation is that afferent inputs ascending to the somatosensory cortex are required for acquiring motor skills which could be supported by direct anatomical projects had been found from somatosensory cortex to the motor, premotor and parietal cortices in monkeys (Jones et al. 1978), and these projections could modulate neuronal activity in the primary motor cortex (Farkas et al. 1999). Sensory deficits could also affect the motor functions in patients with stroke. Indeed, about $53 \%$ of stroke patients were reported to have impaired tactile sensation (Connell et al. 2008).

The Jebsen-Taylor Hand Function Test (JTHFT) is a standardized test measuring hand functions in activities of daily living (ADLs) (Jebsen et al 1969). In the original research by Jebsen et al (1969), JTHFT was used to assess subjects with a variety of disorders such as rheumatoid arthritis, hemiparesis and spinal cord injury. They found the test to have moderate inter-rater reliability $(\mathrm{ICC}=0.60)$ (Jebsen et al 1969). The JTHFT was also capable of differentiating people with rheumatoid arthritis, spinal cord injury and hemiparesis from normal subjects (Jebsen 1969). Although the JTHFT is increasingly used in neurorehabilitation to evaluate the hand functions in patients with stroke,
Correspondence to:
Dr. Shamay S.M. Ng
Department of Rehabilitation Sciences
The Hong Kong Polytechnic University Hung Hom,
Kowloon,
Hong Kong
E-mail: Shamay.Ng@inet.polyu.edu.hk 
Table 1. Inclusion and exclusion criteria.

\begin{tabular}{|l|l|}
\hline \multicolumn{1}{|c|}{ Inclusion criteria } & Exclusion Criteria \\
\hline 1. Age between 55 and 75 years & 1. Medical comorbidity \\
\hline 2. Previous history of stroke 1-10 years ago & 2. Receptive dysphasia \\
\hline 3. Previous history of stroke 1-10 years ago & 3. Pre-existing neurological disorders other than stroke \\
\hline 4. $\begin{array}{l}\text { Discharged from all rehabilitation services at } \\
\text { least } 3 \text { months before the commencement of } \\
\text { this study }\end{array}$ & $\begin{array}{l}\text { 4. Cognitive impairment denoted by scoring }<7 \\
\text { out of } 10 \text { on the Abbreviated Mental Test (AMT) }\end{array}$ \\
\hline $\begin{array}{l}\text { 5. Able to understand instructions and give } \\
\text { informed consent }\end{array}$ & \\
\hline
\end{tabular}

the relationship between sensorimotor impairments and the JTHFT scores had not been investigated before. Because major aim of stroke rehabilitation is to optimize patients' performances of motor tasks in activities of daily living, clinicians need a reliable and valid measurement that will establish patients' upper limb functions at baseline, to monitor patients' progress as a result of treatment. The objective of this study is to delineate possible association between sensorimotor impairments of upper limb (i.e. impairments in upper extremity motor function, muscle strength and tactile sensation of affected upper extremity) and hand functions in ADLs (ie, scores of JTHFT) in persons with chronic stroke. The results of the study will provide insight into the design and evaluation of therapeutic programs targeted at improving hand functions in activities of daily living in communitydwelling stroke patients.

\section{METHOD}

This study was a cross-sectional clinical trial. Nineteen community-dwelling stroke patients were recruited through a local self-help group. Inclusion and exclusion criteria are listed in table 1 . The characteristics of subjects are summarised in tables 2 and 3. The study protocol was approved by the ethics committee of the university, and all subjects provided written informed consent after thorough explanation of the study prior to data collection. The study was conducted according to the Declaration of Helsinki for human experiments. All assessment was explained and administered in Chinese.

\section{OUTCOME MEASURES}

\section{(1) Jebsen-Taylor Hand Function Test (JTHFT)}

The JTHFT consists of seven subtests: writing, cards turning, lifting small objects, simulated feeding, stacking checkers, picking up light cans and picking up heavy cans. The time for completing each subtest was recorded. The total JTHFT score was calculated by adding the time scores of all subtests. Higher scores indicated slower performance of tasks. Subjects were allowed a maximum of 180 seconds to complete each subtest. If the subject could not complete the task within the time allowed, 180 seconds was taken as the time for completing the task (Eliasson et al 2006) as higher scores indicated slower performance of tasks while lower scores indicated better performance.

\section{(2) Fugl-Meyer Assessment of Upper Extremity (FMA-UE)}

Fugl-Meyer Assessment (FMA) is a well-accepted validated test for assessing impairments of motor function in people suffering hemiparesis due to cerebrovascular injuries such as stroke. It was originally developed to assess both upper and lower limb motor functions and balance (Fugl-Meyer et al 1975). Only the upper limb items of FMA (FMA-UE) were used in the present study in order to evaluate upperextremity motor impairment including reflexes, voluntary control of isolated

Table 2. Descriptive statistics of demographic data.

\begin{tabular}{|l|l|}
\hline \multicolumn{1}{|c|}{ Characteristics } & \multicolumn{1}{|c|}{$(\mathbf{n}=\mathbf{1 9})$} \\
\hline Age (years) & $62.0 \pm 6.59$ \\
\hline Gender (M/F) & $12 / 7$ \\
\hline Weight (kg) & $64.57 \pm 12.00$ \\
\hline Height (m) & $1.61 \pm 0.11$ \\
\hline Dominant hand (L/R) & $0 / 19$ \\
\hline $\begin{array}{l}\text { Education } \\
\text { (Primary school or below/secondary 1-3/ secondary 4-7/ } \\
\text { university or above) }\end{array}$ & $7 / 6 / 4 / 2$ \\
\hline Episodes of stroke & $1.32 \pm 0.582$ \\
\hline Years since stroke & $5.37 \pm 0.34$ \\
\hline Stroke side (L/R) & $12 / 7$ \\
\hline Type of stroke (hemorrhagic/ischemic) & $6 / 13$ \\
\hline
\end{tabular}


Table 3: Demographic characteristics of subjects.

\begin{tabular}{|l|l|l|l|l|l|l|l|l|l|l|}
\hline No & Age (y) & Gender & $\begin{array}{c}\text { Dominant } \\
\text { hand }\end{array}$ & $\begin{array}{c}\text { Weight } \\
\mathbf{( k g )}\end{array}$ & $\begin{array}{c}\text { Height } \\
(\mathbf{m})\end{array}$ & $\begin{array}{c}\text { Education } \\
\text { level } \\
\left({ }^{*}\right)\end{array}$ & $\begin{array}{c}\text { Episodes } \\
\text { of stroke }\end{array}$ & $\begin{array}{c}\text { Years } \\
\text { since } \\
\text { stroke }\end{array}$ & $\begin{array}{c}\text { Stroke } \\
\text { side }\end{array}$ & $\begin{array}{c}\text { Type of } \\
\text { stroke(^) }\end{array}$ \\
\hline 1 & 71 & Male & Right & 65.3 & 1.61 & 2 & 1 & 2 & Left & U \\
\hline 2 & 57 & Female & Right & 58.5 & 1.53 & 2 & 1 & 1 & Left & H \\
\hline 3 & 65 & Male & Right & 73.5 & 1.71 & 3 & 1 & 3 & Left & I \\
\hline 4 & 56 & Female & Right & 35.8 & 1.25 & 1 & 1 & 8 & Right & H \\
\hline 5 & 60 & Male & Right & 58.0 & 1.60 & 3 & 1 & 3 & Left & I \\
\hline 6 & 65 & Male & Right & 66.0 & 1.64 & 2 & 2 & 3 & Right & I \\
\hline 7 & 73 & Male & Right & 59.9 & 1.62 & 2 & 3 & 6 & Left & I \\
\hline 8 & 76 & Female & Right & 47.1 & 1.51 & 1 & 1 & 2 & Right & I \\
\hline 9 & 56 & Male & Right & 73.5 & 1.62 & 2 & 1 & 4 & Left & I \\
\hline 10 & 58 & Male & Right & 79.5 & 1.76 & 3 & 1 & 10 & Right & H \\
\hline 11 & 62 & Male & Right & 80.0 & 1.67 & 1 & 2 & 4 & Left & I \\
\hline 12 & 62 & Female & Right & 51.0 & 1.53 & 1 & 1 & 7 & Left & I \\
\hline 13 & 57 & Male & Right & 62.5 & 1.70 & 2 & 1 & 3 & Right & H \\
\hline 14 & 56 & Female & Right & 64.1 & 1.60 & 1 & 2 & 14 & Right & I \\
\hline 15 & 55 & Male & Right & 68.0 & 1.67 & 1 & 1 & 5 & Right & I \\
\hline 16 & 58 & Male & Right & 65.0 & 1.60 & 4 & 1 & 7 & Left & H \\
\hline 17 & 67 & Female & Right & 78.0 & 1.61 & 4 & 1 & 7 & Left & I \\
\hline 18 & 55 & Male & Right & 84.0 & 1.66 & 3 & 1 & 4 & Left & H \\
\hline 19 & 69 & Female & Right & 57.0 & 1.60 & 1 & 2 & 10 & Left & I \\
\hline
\end{tabular}

* 1: Primary school or below / 2: Secondary Grade 1-3 / 3: Secondary Grade 4-7 / 4: University or above $\wedge$ H: Haemorrhagic / I: Ischemic / U: Unknown

movement, and coordination. Subjects were first given instructions and demonstrations before performing the tasks. Their performances were observed and rated by a trained tester in accordance with the criteria set in Fugl-Meyer's original study in 1975 (Fugl-Meyer et al 1975). Individual marks for all items were then totalled. Total score ranges between 0 and 66 , with lower score indicating worse motor function. Duncan et al (1983) reported excellent intra-rater $(\mathrm{r}=0.995-0.996)$ and interrater $(r=0.098-0.995)$ reliability in subjects with chronic stroke. Test-retest reliability was also reported to be excellent $(\mathrm{ICC}=0.97)$. Good correlations were also reported between FMA-UE and Arm Motor Ability Test (functional ability $r=0.94$, quality of movement $r=0.94)$ (Chae et al 2003).

\section{(3) Maximal strength \\ isometric muscle}

The Nicholas Hand Held Dynamometer was used to measure upper limb muscle strength. Excellent test-retest reliability was reported for healthy subjects (ICC $=0.820-0.995$ ) (Magnusson et al 1990). Maximum isometric strength of elbow and wrist flexors and extensors were tested on both affected and unaffected upper limbs. Testing position was listed in table 4. Subjects were instructed to gradually increase force against the tester until maximal contraction was achieved. Maximum contraction was maintained for approximately 5 seconds. Five trials were performed on each muscle group. One minute of rest was given between each trial to minimize the effect of fatigue. The results of the five trials were first averaged. The averaged values were then normalized by body weight for analysis.

\section{(4) Handgrip and pinch grip strength}

The Jamar Hydraulic Hand Dynamometer was used to measure handgrip force and pinch grip force. Excellent inter-rater reliability was reported in handgrip force (ICC $=0.996-0.998$, $\mathrm{p}<0.05$ ) and pinch grip force (ICC = $0.949-0.990, \mathrm{p}<0.05)$ in healthy subjects (Lindstrom-Hazel et al 2009). Testing positions are listed in table 4 .

\section{(5) Tactile sensation}

Semmes-Weinstein Monofilaments was used to evaluate the sensation threshold to light touch. Excellent inter-rater reliability ( $\mathrm{ICC}=0.999$ ) (Novak et al 1993) was reported using monofilament in assessing tactile sensation deficits. 


\begin{tabular}{|c|c|c|}
\hline Action & Position & Dynamometer placement \\
\hline Elbow flexion & $\begin{array}{l}\text { Supine } \\
\text { Shoulder: } 30^{\circ} \text { abduction } \\
\text { Elbow: } 90^{\circ} \text { flexion } \\
\text { Forearm: Supinated }\end{array}$ & $1 \mathrm{~cm}$ proximal to wrist on flexor surface of forearm \\
\hline Elbow extension & $\begin{array}{l}\text { Supine } \\
\text { Shoulder: } 30^{\circ} \text { abduction } \\
\text { Elbow: } 90^{\circ} \text { flexion } \\
\text { Forearm: Supinated }\end{array}$ & $1 \mathrm{~cm}$ proximal to wrist on extensor surface of forearm \\
\hline Wrist flexion & $\begin{array}{l}\text { Sitting } \\
\text { Elbow: } 90^{\circ} \text { flexion } \\
\text { Forearm: Supported \& supinated } \\
\text { Wrist: Neutral } \\
\text { Fingers: Relaxed }\end{array}$ & Just proximal to $3^{\text {rd }}$ metacarpal head on palmar side \\
\hline Wrist extension & $\begin{array}{l}\text { Sitting } \\
\text { Elbow: } 90^{\circ} \text { flexion } \\
\text { Forearm: Support \& pronated } \\
\text { Wrist: Neutral } \\
\text { Fingers: Flexion }\end{array}$ & Just proximal to $3^{\text {rd }}$ metacarpal head on dorsal side \\
\hline Handgrip & $\begin{array}{l}\text { Sitting } \\
\text { Elbow: } 90^{\circ} \text { Flexion } \\
\text { Forearm: Neutral \& } \\
\text { without support }\end{array}$ & / \\
\hline Pinch grip & $\begin{array}{l}\text { Sitting } \\
\text { Elbow: } 90^{\circ} \text { Flexion } \\
\text { Forearm: Neutral \& } \\
\text { without support }\end{array}$ & / \\
\hline
\end{tabular}

Three sites were chosen for the test: tip of index finger, centre of palm, and $1 \mathrm{~cm}$ proximal to MCPJ of middle finger on the dorsal side. These points were chosen because they occupy sites involved in many hand activities. Starting with stiffness of 4.31 , the monofilament was applied perpendicularly to subject's skin until the monofilament started to bend then held in this position for approximately 1 second. Subjects were instructed to answer "Yes" once they felt the pressure. If there was no response, the procedure was repeated five times for each monofilament stiffness. The monofilament was applied in a descending order until the subject no longer felt the stimulus. The previous filament was applied again to reconfirm the sensory threshold. The lower the scores represent the better sensation.

\section{DATA ANALYSIS}

Results were analysed using SPSS 16.0.0 for Windows. Mann-Whitney U test was used to identify differences in measures between affected and unaffected arms.
The distribution of data was checked using a Kolmogorov-Smirnov test of normality. As the data was not normally distributed, Spearman's Rho was used to assess the correlations between different outcome measures. Level of significance was set at $\alpha=0.05$. For Spearman's Rho statistics, $r_{s}=0.00-0.25$ were classified as showing little or no correlation; $\mathrm{r}_{\mathrm{s}}=0.25-0.50$ as fair; $\mathrm{r}_{\mathrm{s}}=0.50-0.75$ as moderate to good; and $r_{s}>0.75$ as good to excellent.

\section{RESULTS}

\section{Subjects}

Nineteen patients with stroke, an average of $62.0 \pm 6.6$ years old (16 men; all right-hand dominant), post-stroke $5.4 \pm 0.3$ years participated in the study. Their demographic data and level of functional mobility of our subjects was shown in Table 2.

\section{The Jebsen-Talyor Hand Function Test}

The total JTHFT scores and scores of all subtests showed significant differ- ences between affected and unaffected sides $(\mathrm{p}<0.001)$. Total JTHFT scores of the unaffected side $(68.61 \pm 16.99)$ were lower than those of the affected side (347.07 \pm 354.49$)$ (Table 5).

\section{Maximum Isometric Muscle Strength}

Comparing affected side with unaffected side, all measurements of elbow and wrist muscle strength showed significant difference ( $p=0.017)$ for normalized wrist extensor, $\mathrm{p}<0.001$ for all others). All measures of maximum isometric strength on the unaffected side were stronger than those on the affected side (Table 5).

\section{Handgrip and Pinch Grip Strength}

Significant differences were found between affected and unaffected sides in both handgrip and pinch grip strength ( $p<0.001$ for both grips). In both handgrip and pinch grip strength, the strength of the affected sides were significantly weaker than the unaffected sides, with the unaffected sides more than twice as strong as the affected sides for both 
Table 5: Mean values of JTHFT, tactile sensation, muscle strength and FMA $(n=19)$.

\begin{tabular}{|c|c|c|c|}
\hline Parameters & Unaffected arm & Affected arm & $p$ \\
\hline \multicolumn{4}{|l|}{ JTHFT: } \\
\hline Total JTHFT score & $68.608 \pm 16.993$ & $347.072 \pm 354.497$ & $<0.001$ \\
\hline Subtest 1 - writing test & $26.843 \pm 13.877$ & $78.008 \pm 46.651$ & $<0.001$ \\
\hline Subtest 2 - page turning & $6.987 \pm 2.082$ & $39.102 \pm 52.068$ & $<0.001$ \\
\hline Subtest 3 - lifting small objects & $9.232 \pm 2.620$ & $48.992 \pm 54.424$ & $<0.001$ \\
\hline Subtest 4 - simulated feeding & $9.087 \pm 2.280$ & $47.419 \pm 60.691$ & $<0.001$ \\
\hline Subtest 5 - stacking checkers & $6.233 \pm 1.924$ & $61.571 \pm 73.475$ & $<0.001$ \\
\hline Subtest 6 - picking up light cans & $4.965 \pm 1.150$ & $34.906 \pm 55.784$ & $<0.001$ \\
\hline Subtest 7 - picking up heavy cans & $5.262 \pm 1.263$ & $37.075 \pm 59.836$ & $<0.001$ \\
\hline FMA total score & I & $47.050 \pm 12.886$ & / \\
\hline \multicolumn{4}{|l|}{ Muscle strength (normalized): } \\
\hline Elbow flexion & $0.179 \pm 0.481$ & $0.116 \pm 0.042$ & $<0.001$ \\
\hline Elbow extension & $0.150 \pm 0.425$ & $0.088 \pm 0.040$ & $<0.001$ \\
\hline Wrist flexion & $0.117 \pm 0.037$ & $0.068 \pm 0.043$ & $<0.001$ \\
\hline Wrist extension & $0.136 \pm 0.053$ & $0.093 \pm 0.049$ & 0.017 \\
\hline Handgrip & $0.444 \pm 0.972$ & $0.171 \pm 0.079$ & $<0.001$ \\
\hline Pinch grip & $0.102 \pm 0.434$ & $0.045 \pm 0.034$ & $<0.001$ \\
\hline \multicolumn{4}{|l|}{ Tactile sensation: } \\
\hline $1 \mathrm{~cm}$ proximal to $\mathrm{MCPJ}$ & $3.105 \pm 0.709$ & $3.513 \pm 0.793$ & 0.075 \\
\hline Centre of palm & $3.330 \pm 0.695$ & $3.442 \pm 0.766$ & 0.908 \\
\hline Tip of index finger & $3.195 \pm 0.552$ & $3.407 \pm 0.898$ & 0.729 \\
\hline
\end{tabular}

measures. Ranges for normalized handgrip on the affected and unaffected sides were $0.06-0.33 \mathrm{Nkg}^{-1}$ and 0.30 $0.74 \mathrm{Nkg}^{-1}$, whereas ranges for normalized pinch grip were $0.00-0.13 \mathrm{Nkg}^{-1}$ and $0.05-0.25 \mathrm{Nkg}^{-1}$ respectively (table 5).

\section{Tactile sensation}

On the three points assessed no differences between sides were found $(\mathrm{p}=$ 0.908 for palm, $p=0.729$ for index finger), though the difference between the two sides at MCPJ approaches statistical significance $(\mathrm{p}=0.075)$ (Table 5).

\section{Correlations with the JTHFT}

No significant correlation was found between the total JTHFT scores and age, weight, height, education level, number of episodes of stroke and years since stroke. Significant moderate negative correlations were also found between the total JTHFT scores with normalized handgrip $\left(r_{s}=-0.588, p=0.008\right)$ and normalized pinch grip $\left(r_{\mathrm{s}}=-0.657\right.$, $\mathrm{p}=0.002)$ strength on the affected side. There was no significant correlation found among the total JTHFT scores, tactile sensation and maximum isometric muscle strength of flexor and extensor of elbow and wrist. Strong significant correlations were found between the total JTHFT score on the affected side and total FMA score under Spearman's analysis $\left(r_{\mathrm{s}}=-0.789, \mathrm{p}<0.001\right)$. The sub-scores of JTHFT were also found to have significant correlations with all but Part I of FMA. Strength of these correlations ranged from fair to good $\left(r_{\mathrm{s}}=-0.482--0.716\right)$. No significant correlation was found between total JTHFT score and muscle strength, grip strength and tactile sensation on the unaffected side (Table 6). 
Table 6: Correlation between total JTHFT score and other measures on ipsilateral side.

\begin{tabular}{|c|c|c|c|}
\hline Parameters & & Spearman $p$ & $p$ \\
\hline Affected hand & $\begin{array}{l}\text { FMA } \\
\text { Total FMA score } \\
\text { Part I reflexes } \\
\text { Part II flexor \& extensor synergies } \\
\text { Part III mixing synergies } \\
\text { Part IV out of synergy } \\
\text { Part VI wrist } \\
\text { Part VII hand } \\
\text { Part VIII coordination } \\
\text { Muscle strength (normalized) } \\
\text { Elbow flexion } \\
\text { Elbow extension } \\
\text { Wrist flexion } \\
\text { Wrist extension } \\
\text { Handgrip } \\
\text { Pinch grip } \\
\text { Tactile sensation } \\
\text { 1cm proximal to MCPJ } \\
\text { Centre of palm } \\
\text { Tip of index finger }\end{array}$ & $\begin{array}{l}-0.789^{\star} \\
0.232 \\
-0.606^{\star} \\
-0.660^{\star} \\
-0.482^{\star} \\
-0.716^{\star} \\
-0.661^{\star} \\
-0.599^{\star} \\
\\
0.047 \\
-0.249 \\
-0.284 \\
-0.042 \\
-0.588^{\star} \\
-0.657^{\star} \\
0.375 \\
0.342 \\
0.158\end{array}$ & $\begin{array}{l}<0.001 \\
0.339 \\
0.006 \\
0.002 \\
0.037 \\
0.001 \\
0.002 \\
0.007 \\
0.847 \\
0.304 \\
0.238 \\
0.864 \\
0.008 \\
0.002 \\
0.114 \\
0.152 \\
0.518\end{array}$ \\
\hline Unaffected hand & $\begin{array}{l}\text { Muscle strength (normalized) } \\
\text { Elbow flexion } \\
\text { Elbow extension } \\
\text { Wrist flexion } \\
\text { Wrist extension } \\
\text { Handgrip } \\
\text { Pinch grip } \\
\text { Tactile sensation } \\
\text { 1cm proximal to MCPJ } \\
\text { Centre of palm } \\
\text { Tip of index finger }\end{array}$ & $\begin{array}{l}0.288 \\
0.084 \\
0.337 \\
0.225 \\
0.333 \\
0.188 \\
\\
0.351 \\
0.241 \\
0.214\end{array}$ & $\begin{array}{l}0.232 \\
0.732 \\
0.158 \\
0.355 \\
0.163 \\
0.442 \\
\\
0.141 \\
0.320 \\
0.378\end{array}$ \\
\hline
\end{tabular}

\section{DISCUSSION}

Our study is the first study to delineate possible association between sensorimotor impairments of upper limb (i.e. impairments in upper extremity motor function, muscle strength and tactile sensation of affected upper extremity) and hand functions in ADLs (ie, scores of JTHFT) in persons with chronic stroke

\section{Muscle strength}

The results obtained from the present study are consistent with previous find- ings that there is a significant difference in strength between sides of the stroke subjects (Chae et al 2003). In a review on clinical and physiological studies with stroke patients, the loss of muscle strength following stroke could be due to decreased capacity to activate motor units, reduced number of functioning motor units, reduced motor units firing rate and increased co-contraction of the antagonists during movement $(\mathrm{Ng}$ and Shepherd 2000).
Results of this study show that the JTHFT scores have a moderate to good correlation with normalized pinch grip $(\mathrm{r}=-0.657, \mathrm{p}<0.01)$ and handgrip $(\mathrm{r}=$ $-0.588, \mathrm{p}<0.01$ ), but not with elbow and wrist muscle strength. This could be explained by the fact that JTHFT focuses mainly on evaluating fine motor hand functions instead of gross motor functions. Effective muscle contraction of hand muscles, as indicated by hand and pinch grip strength, is essential for good hand function. Elbow and wrist muscles 
however, are less involved in fine hand functions. Consistent with previous findings (Sunderland et al 1989), our results support the view that grip strength could also be an important indicator of upper extremity function in persons with chronic stroke. Sunderland et al (1989) reported that grip strength has a good prognostic value for persons with acute stroke. It was found that subjects with better grip strength at one month tended to have a better upper limb function at six months, and grip strength was a valid predictor of upper limb function.

\section{Tactile sensation}

It was surprising to note that that there was no difference in tactile sensation over the 3 selected sites between affected and unaffected hands, because sensory deficit is frequently reported by persons with stroke (Connell et al. 2008). The estimates of prevalence in somatosensory impairment after stroke varied widely from (Connell et al. 2008), and may due to heterogeneity in study populations, the number of somatosensory modalities and body areas assessed. Our results contrasted with the study of Sommerfeld and Arbin, (2004), which found that 39 out of 77 subjects with acute stroke had impaired tactile sensation assessed by light touch with cotton wool. No significant correlation was found between tactile sensation with cotton wool and the total scores of JTHFT for both sides, suggesting that deficits in tactile sensation did not affect hand function. This contradicted the result of a previous study by Ebied et al, (2004), which found significant correlation between impaired tactile sensation induced by artificial cutaneous sensation block and writing $(p=0.02)$. Continuous feedback from afferent input was important for the automatic fine adjustment of hand movement and, the ability to adjust force and direction of movements accurately was essential for performing fine hand functions (Connell et al. 2008). In our study, the three sites tested for tactile sensation may not represent the whole picture of sensory deficiency in individuals with stroke. In addition, different subject types, different assessment method may also affect the result of study.

\section{Correlations between JTHFT and FMA-UE}

Significant correlations were found between total JTHFT score and all but the first and fifth items of FMA-UE. These items of FMA-UE examined upper limb reflexes while the JTHFT examines the functional capacity of hands. One previous study (Woodbury et al 2007) suggested that the reflex items of FMA-UE differed from the rest of the test. While the majority of FMA-UE items assessed voluntary movements, the reflex items were assessing involuntary responses (Woodbury et al 2007). Since all items in the JTHFT involved subjects performing voluntary movements, it was reasonable that there was no correlation between the JTHFT and reflex items of FMA-UE. Similar results with poor correlation between severity of spasticity and motor functions in stroke patients had been found in some previous studies ( $\mathrm{Ng}$ and Hui-Chan 2005). Our negative results may also be due to small sample size and/or to the adoption of compensatory strategy by our stroke subjects, such as increased trunk side flexion to accomplish the upper limb motor tasks.

Strongest correlations were found between total the JTHFT score and sixth and seventh items of FMA-UE $\left(r_{s}=-0.716\right.$ and $r_{s}=0.661$ respectively $)$ which assessed wrist mobility and prolonged isometric muscle contraction, as well as hand functions and grips. The sixth and seventh items of FMA-UE are similar in task nature of the JTHFT and also to hand function, as most hand functions such as writing and picking up objects involves the movement of joints of wrist and hand. In addition, strong significant correlation was found between the total JTHFT scores and most items of FMA-UE. This could be explained by a number of testing items (ie, the sixth and seventh items) between both measurements

\section{Limitations}

Our study did have several limitations. As majority of the subjects recruited in this study were quite active and have a relatively high functional status, results obtained in this study might not be generalized to persons with acute stroke or persons with lower mobility level. Further studies might need to recruit subjects with different functional level. The number of subjects that participated in this study was relatively small. This study was a cross-sectional study, and it did not prove any causality between the JTHFT score and level of different impairments. We only measured tactile sensation in the present study, whether pin-pick sensation or proprioception generating similar result would need further investigation. In addition, a few subjects with more arm impairment could not complete some items of JTHFT within the 180 seconds time limit. A score of 180 seconds was given as suggested by Eliasson et al (2006), and this might overestimate the ability of the subjects. All subjects in this study are right-handed, they may never have used the left hand to write. Therefore the measure of writing speed on the left side (JTHFT Item 1) may not really be measuring their functional ability.

Isometric muscle strength measured in this study may not be functional in our assessment protocol, as most ADL tasks involve movement of joints whilst muscle force is exerted. Previous study showed that shoulder flexors strength had a moderate to excellent correlation with paretic upper limb function (Mercier and Bourbonnais 2004). The present study, however, did not measure muscle strength of shoulder muscles due to limited time, and further studies could include shoulder muscle strength as one of the measurements.

\section{CONCLUSION}

The present study showed that there was a significant difference in hand functions in ADLs, handgrip, pinch grip and maximum isometric strength between affected and unaffected sides, but not tactile sensation. The total JTHFT score was strongly correlated to the total score and all subtests of FMA-UE except measurement of reflex (ie, the first and fifth items). Moderate correlation was also identified between the total JTHFT scores and normalized handgrip and pinch grip on the affected side. These findings indicate that motor recovery and muscle strength of the hands are important for hand function in activities of daily living in persons with chronic stroke. It is important for physiotherapist in designing appropriate intervention 
in improving muscle strength of upper extremity, pinch grip and handgrip in order to improve hand functions in ADLs in patients with chronic stroke.

No commercial party having a direct financial interest in the results of the research supporting this article has or will confer a benefit upon the authors or upon any organisation with which the authors are associated.

\section{Acknowledgments and Funding}

The authors thank the Community Rehabilitation Network of Hong Kong's Society for Rehabilitation for assistance in recruiting subjects.

The study was supported by the Development of Niche Areas Funding to Centre for East-meets-West in Rehabilitation Sciences.

\section{REFERENCES}

Chae J, Labatia I, Yang G 2003 Upper limb motor function in hemiparesis: Concurrent validity of the arm motor ability test. American Journal of Physical Medicine and Rehabilitation 82:1-8.

Connell LA, Lincoln NB, Radford KA 2008 Somatosensory impairment after stroke: frequency of different deficits and their recovery. Clinical Rehabilitation 22:758-767.

Duncan PW, Propst M, Nelson SG 1983 Reliability of the Fugl-Meyer assessment of sensorimotor recovery following cerebrovascular accident. Physical Therapy 63:1606-1610.

Ebied AM, Kemp GJ, Frostick SP 2004 The role of cutaneous in the motor function of the hand. Journal of Orthopedic Research 22:862-886.

Eliasson A, Forssberg H, Hung YC, Gordon AM 2006 Development of hand function and precision grip control in individual with cerebral palsy: A 13 year follow-up study. Pediatrics 118:1226-1236.

Farkas T, Kis Z, Toldi J, Wolff JR 1999 Activation of the primary motor cortex by somatosensory stimulation in adults rats is mediated mainly by associational connections from the somatosensory cortex. Neuroscience 90:353-361.
Fugl-Meyer AR, Jääskö L, Leyman I, Olsson S, Steglind S 1975 The post-stroke hemiplegic patient: A method for evaluation of physical performance. Scandinavian Journal of Rehabilitation Medicine 7:13-31.

Jebsen RH, Taylor N, Trieschmann RB 1969. An objective and standardized test of hand function. Archives of Physical Medicine \& Rehabilitation 50:311-319.

Jones EG., Coulter JD, Hendry SH 1978 Intracortical connectivity of architectonic fields in the somatic sensory, motor and parietal cortex of monkeys. Journal of Comparative Neurology 81:291-347.

Lindstrom-Hazel D, Kratt A, Bix L 2009. Interrater reliability of students using hand and pinch dynamometers. American Journal of Occupation Therapy 63:193-197.

MagnussonSP,GleimGW,NicholasJA1990.Subject variability of shoulder abduction strength testing. American Journal of Sports Medicine 18:349-53.

Mercier C, Bourbonnais D 2004 Relative shoulder flexor and handgrip strength is related to upper limb function after stroke. Clinical Rehabilitation 18:215-221.

Ng SS, Hui-Chan CW 2005 The timed Up \& Go test: Its reliability and association with lower-limb impairments and locomotor capacities in people with chronic stroke. Archives of Physical Medicine and Rehabilitation 86:1641-1647.

Ng SSM, Shepherd RB 2000 Weakness in patients with stroke: Implications for strength training in neurorehabilitation. Physical Therapy Review 5:227-238.

Novak CB, Mackinnon SE, Williams JI, Kelly L 1993 Establishment of reliability in the evaluation of hand sensibility. Plastic and Reconstructive Surgery 92:312-322.

Reed RL, Den Hartog R, Yochum K, Pearlmutter L, Ruttinger AC, Mooradian AD 1993 A comparison of hand-held isometric strength measurement with isokinetic muscle strength measurement in the elderly. Journal of American Geriatric Society 41:53-56.
Sommerfeld DK, Arbin MH 2004 The impact of somatosensory function on activity performance and length of hospital stay in geriatric patients with stroke. Clinical Rehabilitation 18:149-155.

Sunderland A, Tinson D, Bradley L, Hewer RL 1989 Arm function after stroke. An evaluation of grip strength as a measure of recovery and a prognostic indicator. Journal of Neurology, Neurosurgery, and Psychiatry 52:1267-1272.

Wade DT, Langton-Hewer R, Wood VA, SkilbeckCE, Ismail HM 1983 The hemiplegic arm after stroke: Measurement and recovery. Journal of Neurology, Neurosurgery, and Psychiatry 46:521-524.

Woodbury ML, Velozo CA, Richards LG, Duncan PW, Studenski S, Lai SM 2007 Dimensionality and construct validity of the Fugl-Meyer assessment of the upper extremity. Archives of Physical Medicine \& Rehabilitation 88:715-723. 